\title{
Dar o peixe e ensinar a pescar: racionalidade limitada e políticas de combate à pobreza ${ }^{1}$
}

\author{
Marcio José Vargas da Cruz ${ }^{2}$ \\ Huáscar Fialho Pessali ${ }^{3}$
}

\section{Resumo}

Este artigo discute algumas implicações em se considerar limitações na racionalidade dos agentes econômicos em suas decisões enquanto beneficiários de programas de combate à pobreza. Tais implicações são ilustradas do Programa Bolsa Família. Parte-se da hipótese tradicional de que ninguém melhor do que o beneficiário para tomar suas decisões referentes à alocação de recursos. Sua decisão, porém, pode vir a ser melhorada, caso seu rol de opções seja ampliado por meio de maior acesso a informações e melhor capacitação para a tomada de decisão em direção ao sustento próprio. Discute-se, por fim, a importância de se considerar tais implicações na elaboração e execução da política pública, com especial atenção ao Bolsa Família.

Palavras-chave: Políticas públicas; Racionalidade limitada; Pobreza; Teoria da perspectiva; Programa Bolsa Família.

\section{Abstract \\ Give a man a fish and teach him to fish: public policies toward poverty reduction with rationally bounded beneficiaries}

This paper discusses the implications of the assumption that economic agents at the receiving end of poverty reduction policies have bounded rationality. It assumes that the beneficiary of the program knows best how to use his or her income to satisfy his or her needs. This, however, does not imply that an optimal solution is reached. Individuals, especially those on very low-incomes, can make better choices as more and better information becomes available, improving their decision-making capabilities in favor of higher income alternatives that can be brought about by their own work efforts. These insights are in turn applied to study the case of the Brazilian program Bolsa Familia, implying that the design and implementation of poverty reduction policies need re-thinking in terms of their long term social efficiency.

Keywords: Public policy; Bounded rationality; Poverty reduction; Prospect theory; Bolsa Família Program.

JEL D20, H53, J38.

(1) Trabalho recebido em janeiro de 2008 e aprovado em novembro de 2009.

(2) Professor do Departamento de Economia da Universidade Federal do Paraná, Curitiba, PR, Brasil E-mail: marciocruz@ufpr.br.

(3) Professor Adjunto do Departamento de Economia da Universidade Federal do Paraná, Curitiba, PR, Brasil. E-mail: pessali@ufpr.br.

$$
\text { Economia e Sociedade, Campinas, v. 20, n. } 1 \text { (41), p. } 141-166 \text {, abr. } 2011 .
$$




\section{Introdução}

A elaboração de políticas de combate à pobreza pode encontrar contribuições relevantes no campo de estudo da microeconomia. Um exemplo é a teoria da escolha racional aplicada ao consumidor. Por meio de um método dedutivo, demonstra-se que políticas de transferência de renda sob a forma monetária são uma opção mais eficiente de política distributiva, visando a aumentar o bem-estar de um indivíduo, do que intervenções de mercado ou doação de cestas de produtos.

Parte-se do princípio de que o melhor é o próprio indivíduo definir o que lhe é ideal. Sendo racional, ele determina, inequivocamente, o grau de prioridade de suas preferências. Assim, uma política compensatória baseada na distribuição de cestas de alimentos teria menor chance de maximizar sua utilidade na alocação do mesmo recurso, impelindo o indivíduo a uma segunda rodada de trocas. Se a política escolhe inicialmente os bens pelas famílias, estas os trocarão por outros que venham a maximizar sua utilidade de acordo com suas preferências e com a restrição dada pelo valor da cesta. A segunda rodada de trocas resulta em custos de transação adicionais aos da distribuição da cesta ou relativos à simples transferência monetária. Tais custos poderão reduzir o valor da dotação inicial contido na cesta de bens e por isso as famílias optarão por receber um valor menor, desde que em dinheiro.

Em resumo, o raciocínio originado na economia normativa por meio da teoria convencional do consumidor sugere ao elaborador de políticas públicas optar pela transferência de renda sob a forma monetária. Trata-se de uma contribuição importante com ampla aceitação em esferas de decisões políticas.

Este ensaio propõe-se a discutir possíveis implicações em se relaxar a hipótese de racionalidade substantiva dos beneficiários. Quais seriam, portanto, as consequências sobre a elaboração de uma política social de transferências, partindo-se da hipótese de racionalidade limitada de seus beneficiários? Vislumbram-se de início, modificações sobre a própria definição da política.

A hipótese de que ninguém melhor do que o beneficiário para saber qual cesta the proporciona o maior nível de satisfação é mantida. Considerando-se, porém, limites de racionalidade, sua decisão poderá ser alterada se o programa oferecer também maneiras de aprimorar a qualidade das informações existentes, expandir a competência dos beneficiários para lidar com as mesmas e reduzir a incerteza de determinados rumos de ação. Nessa direção, será incorporada à discussão a ideia de "paternalismo libertário" apresentada por Sunstein e Thaler (2003).

Não se entende, em termos teóricos, que o indivíduo possa aumentar, infinitamente, seu bem-estar ao se relaxar tal hipótese, isto é, há cestas melhores 
ou piores para ele dentro de uma restrição orçamentária. Não fosse assim, para resolver a pobreza, bastaria fazer com que tomasse decisões adequadas a qualquer nível de renda. Propõe-se que dada uma dotação inicial, prover liquidez por excelência não garante que pessoas adquiram a cesta que maximiza seu bem-estar. Isso se deve a limitações com as quais se deparam com relação a conhecer uma solução que otimize seu bem-estar. A transferência de renda é, portanto, uma condição necessária, mas não suficiente.

Essa discussão pode ser ilustrada com o Programa Bolsa Família (PBF). O PBF é um programa de transferência direta de renda a famílias pobres e extremamente pobres, mas que estabelece aos beneficiários condicionalidades relativas à educação, à saúde e às condições sociais da família. Em outras palavras, o PBF toma certas decisões pelo beneficiário por meio das condicionalidades ao invés de simplesmente dar-lhes um equivalente monetário.

O âmbito da discussão aqui proposta é o planejamento econômico, buscando conversar com aqueles que, de uma forma ou outra, atuam na idealização e formulação de políticas públicas. Afinal, é possível que essas pessoas venham a tomar decisões importantes sem que, por vários motivos, possam discutir seus fundamentos microeconômicos. Tenta-se aqui, então, contribuir para que isso seja feito.

\section{0 mecanismo das políticas compensatórias}

Eficiência alocativa e justiça distributiva são temas constantes no debate econômico e fazem-se presentes na discussão a respeito das alternativas de organização de uma sociedade. Ambas têm importantes efeitos na formação dos sistemas econômicos vigentes na maior parte dos países.

Dentre as alternativas propostas e testadas por diversas sociedades ao longo do tempo, as principais instituições envolvidas na construção e distribuição dos resultados econômicos do mundo contemporâneo são o mercado, as firmas e o Estado (Pessali; Fernández, 2006). A atuação e interação dessas instituições no âmbito da promoção da eficiência alocativa e justiça distributiva, bem como seus efeitos sobre o bem-estar social são parte expressiva do objeto de estudo da Economia.

Não há uma economia de mercado completamente independente da intervenção do Estado. Há, por exemplo, políticas públicas que visam a compensar algum tipo de exclusão gerada por mecanismos socioeconômicos de alocação de recursos. Isso é resultado do reconhecimento de que o mercado por si só não é capaz de garantir um nível adequado de satisfação social no que se refere à alocação eficiente e distribuição justa de recursos. 
Ao abarcar, porém, esses dois problemas, surge uma questão delicada para o objeto da economia como ciência: o que é uma distribuição socialmente justa? Não é objetivo do trabalho, tratar de questão tão complexa. Vale ter em mente, contudo, que as pessoas tendem a se deparar com critérios de justiça construídos por meio de valores morais e da organização social constituída em busca da determinação daquilo que é justo.

Cabe lembrar aqui o artigo $3^{\circ}$ da Constituição da República Federativa do Brasil de 1988:

Art. $3^{\circ}$ - Constituem objetivos fundamentais da República Federativa do Brasil:

I - construir uma sociedade livre, justa e solidária;

II - garantir o desenvolvimento nacional;

III - erradicar a pobreza e a marginalização e reduzir as desigualdades sociais e regionais;

IV - promover o bem de todos, sem preconceitos de origem, raça, sexo, cor, idade e quaisquer outras formas de discriminação.

A erradicação da pobreza é, portanto, um dos objetivos explícitos e fundamentais da República Brasileira. Percebendo-se que o resultado esperado não tem sido alcançado pela expansão dos mercados apenas, entende-se caber ao Estado a preocupação com outros mecanismos. Alguns deles envolvem a implementação de determinado tipo de política compensatória. ${ }^{4}$

O diagnóstico de um grande contingente de pessoas vivendo abaixo da "linha de pobreza" de forma persistente, apesar da expansão da economia de mercado, legitima constitucionalmente a ação direta do Estado por via das políticas sociais que visam à erradicação da pobreza. ${ }^{5}$ Pragmaticamente, vê-se que o diagnóstico reflete um critério de justiça distributiva. Toda pessoa residente neste país tem o direito de não estar abaixo da linha de pobreza absoluta, cabendo ao Estado tomar para si tal responsabilidade. ${ }^{6}$

Tem-se, portanto, prevista e requerida a atuação do Estado diante de problemas sociais de larga escala para os quais a expansão dos mercados não

(4) Um debate de longa data recai sobre o formato de tais políticas: se universalizadas ou focalizadas (Kerstenetzky, 2006; Monnerat et al., 2007).

(5) Como argumenta Rocha (2003), a pobreza é um fenômeno complexo, podendo ser definido de forma geral como a situação na qual as necessidades elementares de sobrevivência não são atendidas de forma adequada. Para operacionalizar essa noção geral, é preciso especificar quais são as necessidades e que nível de atendimento é considerado adequado. Assim, a linha da pobreza poderá ser vista como um ponto de corte que especifica a adequação desses elementos em dada sociedade, podendo, portanto, ser tratada de forma absoluta ou relativa.

(6) O valor da linha de pobreza absoluta depende da metodologia adotada quanto à quantidade mínima de calorias diárias necessárias a um indivíduo (Rocha, 2003).

Economia e Sociedade, Campinas, v. 20, n. 1 (41), p. 141-166, abr. 2011. 
garante respostas satisfatórias ao cumprimento de alguns dos objetivos constitucionais. Tem-se também estabelecida a prioridade para a alocação dos recursos públicos a partir de um determinado critério de justiça distributiva. Assim, ao elaborador de políticas públicas é posto o desafio de especificar uma forma eficiente para a alocação dos recursos públicos voltados a tais objetivos. ${ }^{7}$

A partir desse contexto, a próxima seção buscará na teoria microeconômica alguns fundamentos relativos ao comportamento dos indivíduos no que se refere aos processos de decisão para alocação de recursos. Pretende-se, com isso, evocar elementos teóricos que contribuam para o trabalho do elaborador de políticas públicas.

\section{A teoria da escolha do consumidor e suas implicações para as políticas de alívio à pobreza}

Há uma pergunta importante confrontada pelo elaborador de políticas de alívio à pobreza e discutida na literatura teórica: com vistas a melhorar o bemestar de pessoas na pobreza, é preferível dar-lhes dinheiro ou uma cesta de produtos?

A partir da visão da racionalidade substantiva é possível demonstrar que a transferência de dinheiro é a mais eficiente das opções. Partindo-se da teoria da escolha do consumidor, supõe-se que os indivíduos são plenamente racionais e podem ordenar clara e inequivocamente o que fazer com o dinheiro. Assim, diante da limitação de seu orçamento, eles podem escolher a combinação de bens que maximiza seu bem-estar.

Para que a hipótese da racionalidade seja consistente dentro do conjunto de opções possíveis, algumas condições precisam ser satisfeitas:

a) dadas duas opções quaisquer $\mathrm{A}$ e $\mathrm{B}$, o agente prefere $\mathrm{A}$ à $\mathrm{B}$, ou prefere $\mathrm{B}$ à $\mathrm{A}$, ou o agente é indiferente entre $\mathrm{A}$ e $\mathrm{B}$, ou seja, as preferências são completas;

b) se o agente prefere $\mathrm{A}$ à $\mathrm{B}$, e $\mathrm{B}$ à $\mathrm{C}$, então ele prefere $\mathrm{A}$ à $\mathrm{C}$, portanto, as preferências são transitivas.

(7) Sob essa ótica, todo problema de alocação de recursos deve, em última instância, contemplar eficiência alocativa. Não se quer dizer que o conceito de justiça distributiva deva ser relegado com base em critérios como "ser justo é ser eficiente" ou "justiça e eficiência são incompatíveis". A alocação de recursos é vista em dois estágios. No primeiro, decide-se sobre a distribuição dos resultados econômicos. Uma vez decidida a ordem de prioridades das ações públicas, supõe-se que a justiça distributiva tenha sido definida. Busca-se, a partir daí, a eficiência na obtenção do objetivo a ser atingido. Justiça e eficiência são vistas em patamares analíticos diferentes e eficiência é tida como "eficiência em cumprir um propósito" (Le Grand, 1991). 
Satisfeitas as condições, é, então, possível estabelecer o conjunto de cestas que proporciona o mesmo nível de bem-estar ao consumidor. Graficamente, elas são ilustradas pelas chamadas curvas de indiferença.

Supondo-se que o governo do País A, com uma economia de mercado, depare-se com uma elevada desigualdade de renda e um contingente expressivo da população vivendo abaixo de certa linha de pobreza, o diagnóstico da situação sugere dois problemas. Um será de ordem estrutural e o outro, de ordem conjuntural. $\mathrm{O}$ de ordem estrutural diz respeito à saída das pessoas da linha de pobreza de forma permanente ou sustentável. Isso requer que obtenham a renda necessária com a venda de sua força de trabalho, produzindo algo que venha a ser comercializado de forma lucrativa ou do serviço de alguma propriedade. Quanto ao problema de ordem conjuntural tendo a justiça distributiva como um dos objetivos de ordem econômica, não será aceitável que as pessoas permaneçam nessa condição até que se resolva o problema estrutural. Isso é representado de maneira simplificada pela Figura 1.

Figura 1

Processo de tomada de decisão por uma política pública

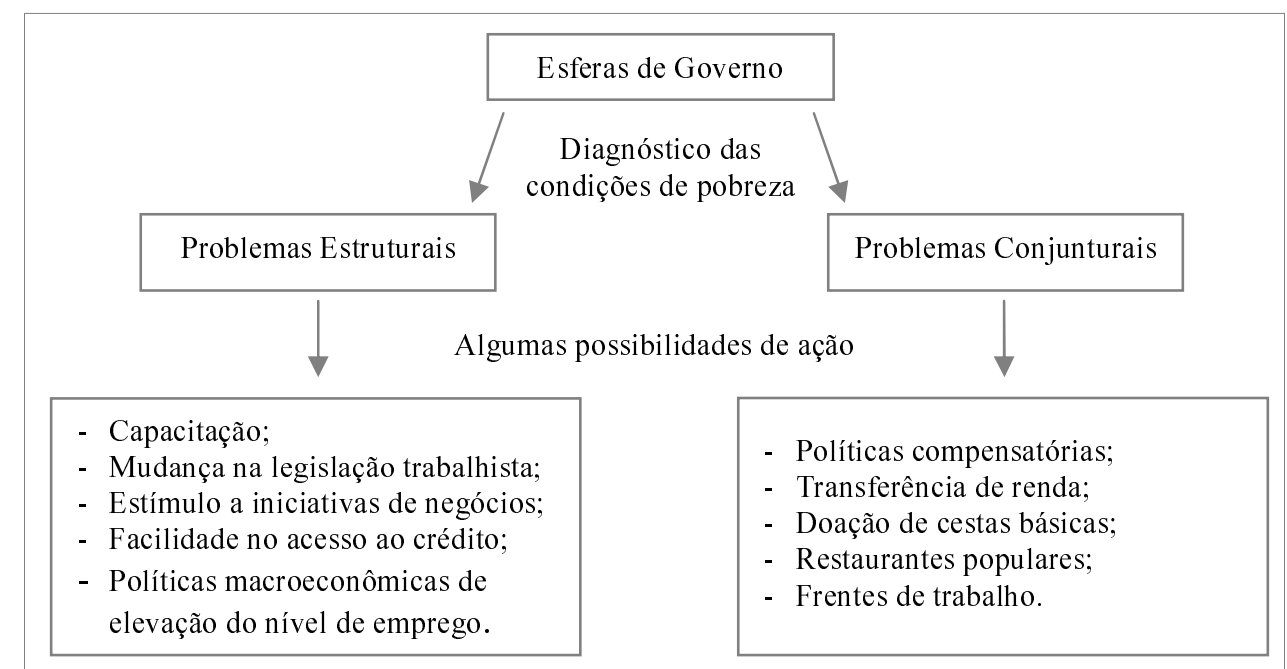

Fonte: Elaboração própria.

Destaque-se para o momento a decisão frente aos problemas conjunturais. Considerando preferências bem comportadas e a hipótese de não saciedade, têm-se as condições de maximização da escolha, das quais se deduz que dentre as opções apresentadas, a mais interessante é a transferência de renda. A Figura 2 exemplifica essa lógica. 
Dar o peixe e ensinar a pescar: racionalidade limitada e políticas de combate à pobreza

Figura 2

Escolha da cesta ótima por parte do consumidor

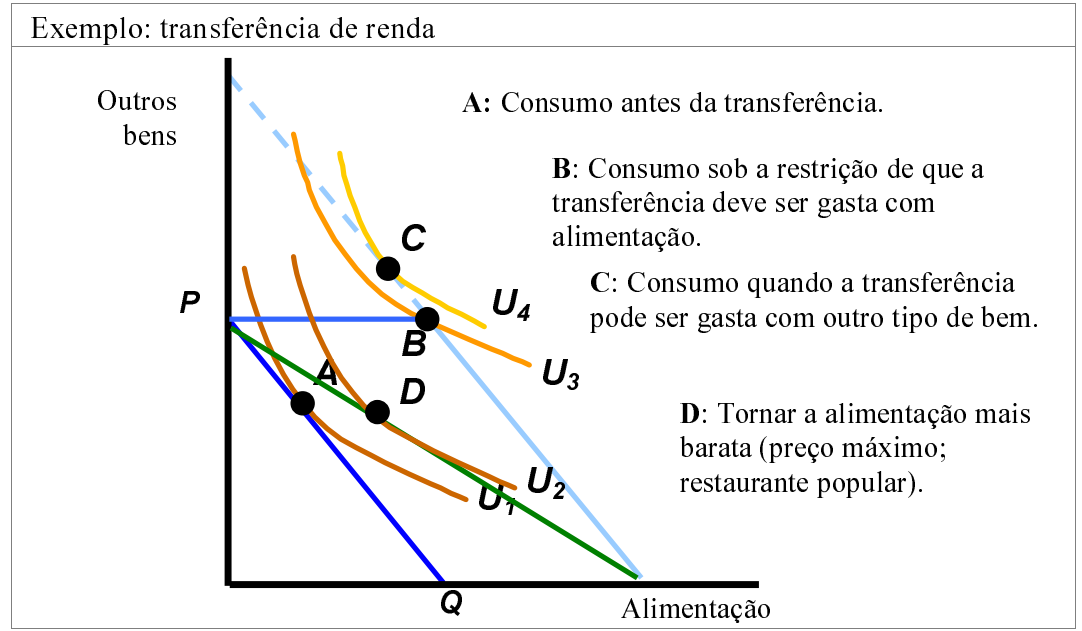

Considerações:

- Suponha uma garantia de preço máximo que reduza os gastos com alimentação ou que sejam disponibilizados restaurantes populares, gerando o mesmo resultado.

Fonte: Elaboração própria.

Supondo-se que a renda inicial do indivíduo the possibilite adquirir a cesta A, com certa quantidade de alimentos e outros bens, seu nível de satisfação será maximizado com a escolha. Se essa renda, entretanto, estiver abaixo da linha de pobreza, a cesta $\mathrm{A}$, apesar de ser a melhor possível, não proverá suas necessidades básicas.

Levando em conta questões de justiça distributiva, o governo opta por uma política compensatória, permitindo ao indivíduo alcançar uma cesta melhor que garanta o atendimento mínimo de suas necessidades. É preciso supor que, para isso, uma renda adicional de $\mathrm{R} \$ 100$ seja suficiente. Essa decisão traz à tona o problema de eficiência alocativa, ou seja, qual a forma mais eficiente de viabilizar a melhor cesta. Isso leva a uma situação tal qual ilustrada na Figura 2 com quatro alternativas a serem consideradas pelo Estado:

a) transferência de renda;

b) doação de cestas básicas;

c) restaurantes populares;

d) políticas de preço máximo. ${ }^{8}$

Considerando-se agora a Figura 3, vê-se de imediato que o indivíduo prefere as cestas $\mathrm{B}$ e $\mathrm{C}$ às cestas $\mathrm{A}$ e $\mathrm{D}$. Se o mecanismo de transferência de renda

(8) Outras alternativas podem, obviamente, ser consideradas. 
é um cartão para gastos com alimentos que possibilite uma renda adicional equivalente a $\mathrm{R} \$ 100$, ele poderá escolher a cesta $\mathrm{B}$, a melhor opção diante da restrição de gastos em alimentos. A mesma utilidade seria proporcionada pela cesta $\mathrm{F}$, originada pela troca do cartão de $\mathrm{R} \$ 100$ por outros bens a uma dada taxa de desconto (equivalente a, digamos, $\mathrm{R} \$ 480$ ). Essa é uma restrição orçamentária mais forte, mas permite total liberdade de escolha. Se for possível, portanto, trocar o cartão de $\mathrm{R} \$ 100$ em alimentos por qualquer valor maior do que $\mathrm{R} \$ 480 \mathrm{em}$ dinheiro, o indivíduo atingirá um nível de satisfação maior. Isso corresponde a alcançar uma curva de indiferença acima da curva U3, mas ainda abaixo de U4. Diante de tais condições, a melhor opção é a de transferir a renda sem restrições, mantendo a liberdade do indivíduo de escolher sua cesta de consumo.

Figura 3

Escolha da cesta ótima por parte do consumidor

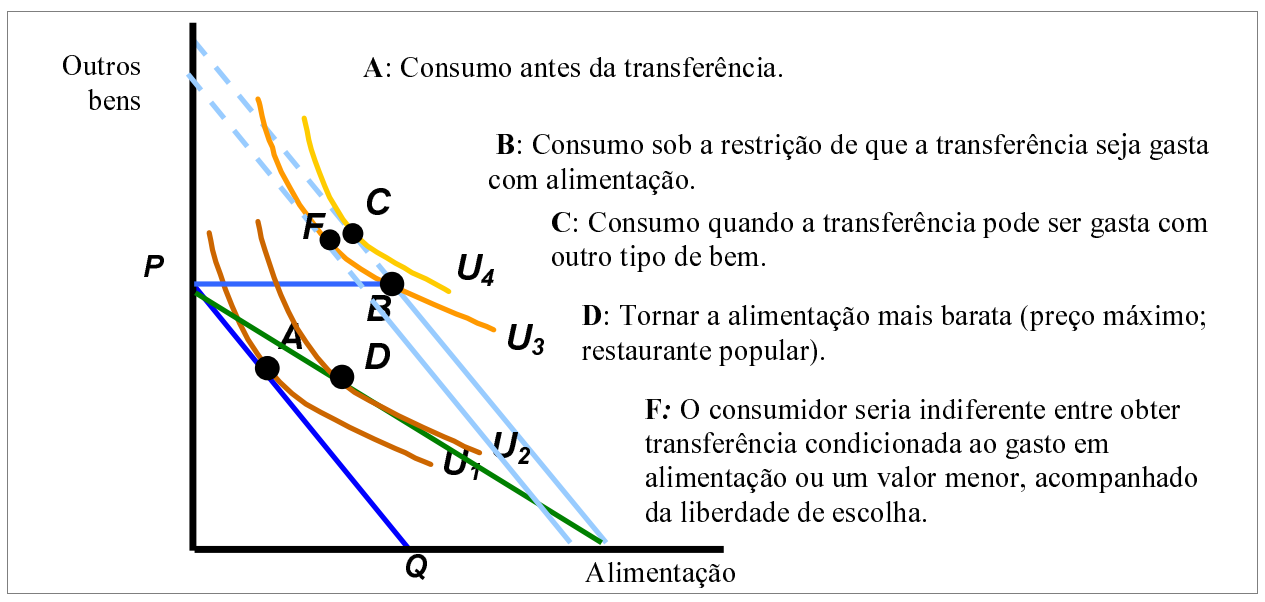

Considerações:

- Imagina-se uma garantia de preço máximo, que reduza os custos com alimentação ou então se faça opção pela construção de restaurantes populares que gerem o mesmo resultado.

Fonte: Elaboração própria.

Na teoria normativa, o resultado é assim obtido. Em termos descritivos, porém, resta a questão: o beneficiário da transferência de renda de fato maximiza seu nível de bem-estar ao ter a opção de escolha para alocação do recurso ou é ainda possível melhorar seu bem-estar?

As seções seguintes apresentam contribuições teóricas que contemplam outros aspectos relevantes à tentativa de responder a tal pergunta, alguns desconsiderados pelo modelo tradicional de tomada de decisão. Na sequência, discutem-se quais seriam algumas das possíveis implicações em se tentar superar tais limitações na decisão de políticas compensatórias. 


\section{Racionalidade limitada, informação e construção de preferências na elaboração de políticas compensatórias}

$\mathrm{Na}$ ótica tradicional, uma definição restrita de bem-estar do beneficiário é tomada como única variável relevante. Tal avaliação, embora útil, tem limitações que precisam ser discutidas. Primeiro, desconsidera-se que o indivíduo possa ter conhecimento limitado a respeito da cesta ótima das cestas alternativas e que, melhorar seu estoque de informação, lhe é custoso. Segundo, pressupõe-se que ele tenha racionalidade ilimitada para processar as informações detidas e antecipa o resultado ótimo de suas escolhas. Terceiro, desconsidera-se a potencial influência do programa sobre as preferências dos beneficiários, seus aspectos positivos e o custo de oportunidade de não utilizá-la.

Com relação à primeira limitação, relaxar a hipótese de informação perfeita tem implicações na eficiência social da transferência de renda. $\mathrm{O}$ custo da informação é deixado sob responsabilidade do beneficiário. Diante do Paradoxo da Informação de Arrow só se pode saber seu valor depois de obtê-la. Beneficiários de baixa renda tenderão a não comprometer sua renda na compra de informação diante da premente necessidade de consumo de outros bens. Os custos adjacentes a se obter informações (e.g. usar o telefone, pegar um ônibus para ir ao mercado) podem desencorajar ainda mais o beneficiário a informar-se sobre a cesta de produtos que consome ou sobre cestas alternativas. As opções do beneficiário são, então, 1) deter-se à cesta de bens já consumida (sem que se reavalie que cesta é essa ou como se chegou a ela); ou 2) arcar com os custos de informação referentes à possibilidade de se buscar uma cesta de consumo alternativa e de utilidade potencialmente maior.

A segunda limitação deriva a hipótese de que os indivíduos têm racionalidade ilimitada para processar as informações que detêm e antecipar o resultado ótimo de suas escolhas. Sobre ela, vale recorrer observações feitas por Herbert Simon (1947, p. 81), pois identificam algumas restrições à racionalidade objetiva no processo decisório:

(1) Rationality requires a complete knowledge and anticipation of the consequences that will follow on each choice. In fact, knowledge of consequences is always fragmentary. (2) Since these consequences lie in the future, imagination must supply the lack of experienced feeling in attaching value to them. But values can be only imperfectly anticipated. (3) Rationality requires a choice among all possible alternative behaviors. In actual behavior, only a very few of all these possible alternatives ever come to mind.

Pode-se, assim, imaginar que relaxar a hipótese de racionalidade ilimitada do beneficiário também terá impacto sobre a eficiência social da transferência de 
renda. ${ }^{9}$ Em primeiro lugar, deixa-se de considerar, por exemplo, os custos de processamento da informação e o potencial caráter coletivo da decisão de alocação da renda (e.g. marido e esposa precisam negociar a alocação). Em segundo lugar, um dos componentes da racionalidade limitada dos beneficiários pode ser resultante simplesmente de sua inabilidade em processar informações mais complexas (e.g. que exigiriam maiores habilidades literárias ou numéricas obtidas através de educação formal). Isso tanto desencoraja quanto incapacita a busca por mais informações. Em terceiro lugar, a racionalidade limitada implica na formação de hábitos e rotinas como mecanismos de predisposição à ação. Por um lado, pode-se vislumbrar o problema dos hábitos nocivos no longo prazo (e.g. fumo e consumo de bebidas alcoólicas) e de certas práticas instituídas (e.g. jogos de azar) que, em geral, têm efeito regressivo sobre as rendas e podem ter consequencias deletérias em populações de baixa renda. Por outro lado, os hábitos têm características de inércia que resultam em buscas limitadas por novas informações, mesmo que haja alguma predisposição para se avaliar novos bens ou novas cestas.

Por fim, vale ressaltar o que a economia experimental tem sugerido a respeito do comportamento dos agentes. Kahneman (1994) e Kahneman e Tversky (1973), dentre outros, estudaram como a capacidade de perceber, racionalizar e atuar sobre um problema depende de como este é apresentado. Não bastasse isso, a memória limitada impede que todas as deliberações insatisfatórias sejam corrigidas. Como resultado, mesmo pessoas bem informadas cometem desvios sistemáticos de escolha ótima. O Nobelista Daniel Kahneman (1994, p. 33) conclui, por exemplo, que há espaço para "intervenções paternalistas quando é plausível que o estado saiba mais sobre os gostos futuros do indivíduo do que o próprio indivíduo saiba no momento presente". ${ }^{10}$

Com relação à terceira limitação, desconsiderar a potencial influência dos programas sobre as preferências dos beneficiários tem implicações na eficiência social da transferência de renda. Uma vez montada certa estrutura organizacional para a execução e monitoramento de um programa de transferência de renda, é possível fazer uso da mesma para transferir certos tipos de informação aos beneficiários a custos muito mais baixos do que seria a somatória dos potenciais custos a se incorrer pelos mesmos, individualmente, para obter a mesma informação. Um programa social estruturado pode ter economias de escala e escopo, além de maior capacitação técnica e legitimidade institucional para acessar, reunir, processar e disponibilizar informações mais específicas.

(9) Não se considera aqui o fato de o planejador, também, ter racionalidade limitada para decidir que o programa de renda é o mais eficiente.

(10) A este respeito, ver também Sunstein e Thaler (2003). 
Assim, uma política compensatória de combate à pobreza que atua apenas por meio da concessão de renda direta é menos eficiente do ponto de vista do bemestar social. Afinal, ela deixa de utilizar recursos já mobilizados que poderiam, também, 1) levar informações de maneira menos custosa aos beneficiários e ampliar seu rol de escolhas; 2) ajudar a amenizar problemas de racionalidade limitada tanto por parte dos planejadores quanto dos beneficiários.

A política compensatória que apenas transfere dinheiro, embora amplie o rol inicial de escolhas dos indivíduos, limita-se a dar potencial acesso, no curto prazo, a uma cesta mais ampla de produtos. Tal política, porém, não estimula o engajamento dos beneficiários em atividades que possam proporcionar-lhes ampliação da renda e do rol de escolhas no longo prazo. Isso, ao fim, pode criar uma armadilha da pobreza.

Ao admitir-se que o beneficiário tem informação limitada (e que economias de escopo não são utilizadas pelo programa para reduzir tal limitação), vê-se que a transferência simples de renda parece ser capaz de proporcionar, no máximo, um ótimo local de curto prazo ou um equilíbrio estacionário dentro da armadilha da pobreza (e.g. no limite superior da renda concedida pelo programa).

Cabe ressaltar, no que diz respeito à potencial influência do programa sobre as preferências dos beneficiários, que o instrumento estático da teoria normativa poderá ser insuficiente para promover a discussão de outras possibilidades do mesmo. Uma revisão das premissas a respeito do comportamento dos indivíduos, por exemplo, permite que se considere a possibilidade de 1) reduzir custos de informação com melhor aproveitamento de economias de escopo oriundas de uma estrutura já montada para execução de um programa mais restrito; 2) aprendizado por parte do beneficiário e do programa; 3) uso da memória organizacional do programa em auxílio às limitações de memória do indivíduo. Todas estas possibilidades apontam para a capacidade de uma política compensatória em atuar sobre as preferências dos beneficiários. A discussão, portanto, passa a incorporar alternativas de ações com efeitos no médio e no longo prazo.

Retornando à questão das opções do governo em atuar frente aos problemas conjunturais, observa-se que a dinâmica da melhoria sustentável requer que as respostas a tais problemas estejam em harmonia com as propostas para lidar com os problemas estruturais. As ações que visam a sanar problemas no curto prazo por meio de mecanismo compensatório, portanto, terão efeitos no longo prazo, assim como, por princípio, é de se esperar que mudanças estruturais influenciem os problemas conjunturais do futuro. 
A partir dessa posição, retorna-se ao problema anterior. O Estado implementa ações concretas dirigidas aos problemas conjunturais, mas parte de novas premissas como a racionalidade limitada do beneficiário, a assimetria e a incompletude da informação e, também, a possibilidade de atuar sobre as escolhas dos indivíduos. Diante de tais considerações, o Estado coloca-se em melhores condições para incorporar a correlação entre problemas conjunturais e estruturais. Mantendo-se a restrição quanto às opções de ações dirigidas aos problemas conjunturais, a pergunta que agora se faz é: o mecanismo de transferência de renda permanece como a opção mais interessante? Essa é uma questão que envolve o desenho do mecanismo e das instituições que fazem um programa funcionar.

\section{Desenho institucional e paternalismo libertário}

Os problemas apresentados até aqui mostram as dificuldades enfrentadas pelo indivíduo na tomada de decisão com vistas a melhorar seu bem-estar. Tais dificuldades têm implicações em resultados auferidos por uma política compensatória, ou seja, as hipóteses assumidas pelo planejador a respeito do comportamento dos beneficiários terão impacto sobre os resultados conjunturais e estruturais da política pública em questão.

Isso implica em dizer que, mesmo em uma política compensatória que envolva transferência de renda na forma monetária, o planejador, ao desenhar o mecanismo de transferência, já tomou uma decisão no lugar do beneficiário. Tais decisões são inevitáveis e indicam algum grau de paternalismo, ou seja, de uma escolha feita "no intuito de influenciar as escolhas das partes afetadas de modo a melhorar seu bem-estar" (Thaler; Sunstein, 2003, p.175). A questão central não é mais "ser paternalista ou não", mas como exercer o paternalismo.

Vários estudos têm mostrado que as decisões tomadas pelas pessoas são sensíveis à forma de apresentação dos problemas e das opções (Kahneman et al., 1991; Tversky; Kahneman, 1986; Madrian; Shea, 2001). Um viés consistentemente apresentado pelas pessoas é permanecer na opção default (Choi et al., 2003). Se, portanto, o desenho de um programa de transferência de renda quiser, ao mesmo tempo, ser não impositivo (dar liberdade de escolhas) e proporcionar escolhas melhores, a determinação de uma opção default poderá ser importante. Imagina-se uma situação em que o planejador encontra respaldo para incentivar determinada escolha, acreditando ser a melhor informada, a mais benéfica ao beneficiário (e.g. merenda escolar com maior valor nutritivo, acompanhamento pré-natal, ingresso e permanência na escola ou maior capacitação profissional). A inércia apresentada pelas pessoas e a possibilidade de determinar uma opção default podem ser aproveitadas para o desenho do programa, tendo impacto sobre seus resultados conjunturais e estruturais. 
Voltando ao objeto de discussão, quer-se considerar a possibilidade de uma dinâmica no comportamento dos beneficiários a partir da melhoria do conjunto de informações a eles disponibilizado mesmo que, em dado momento, suas preferências estejam dadas. $\mathrm{O}$ fato é que poderiam ser diferentes quando relaxadas as hipóteses de racionalidade e assimetria de informação, havendo espaço para incitar mudanças de preferências. Nesse caso, não é preciso desfazer a hipótese de que "ninguém melhor do que o próprio indivíduo para saber como melhorar seu bem-estar". Adiciona-se, entretanto, a seguinte premissa: "mas ele pode melhorar sua decisão, embora não se possa, normativamente, garantir que o fará quando as cestas colocadas a seu alcance sejam montadas por alguém melhor informado".

Nesse momento, pode-se retornar ao problema de maximização de utilidade a partir da transferência de renda na forma monetária e imaginar que a tal ação é adicionada outra, "estrutural", fornecendo maior quantidade de informações ou incentivando a capacitação do beneficiário. Isso poderá permitir que ele alcance maior nível de bem-estar e que o processo siga para uma solução sustentável. Assim, pode-se até aceitar que exista algum ponto de bem-estar ótimo ao indivíduo, dadas as suas preferências. Mantendo-se, porém, tudo o mais constante, melhor capacidade para tomar decisões e maior quantidade de informações podem levar a mudanças de preferências e, consequentemente, de sua cesta de consumo. Essa simples observação torna-se interessante por trazer o relaxamento de duas hipóteses importantes para a teoria convencional da escolha.

Como, então, tais elementos poderão manifestar-se na forma de uma política pública? O Programa Bolsa Família (PBF) oferece um estudo de caso interessante. O PBF exige dos beneficiários uma contrapartida (ou delega corresponsabilidade) que se acredita servir ao aumento de seu bem-estar futuro. Isso o caracteriza como um programa de transferência condicionada de renda com a "aquisição" obrigatória de serviços de saúde, educação e seguridade social. Na próxima seção, identifica-se como o $\mathrm{PBF}$ incorpora questões relativas à racionalidade limitada e à assimetria de informação no processo de decisão dos beneficiários.

\section{Uma análise do Programa Bolsa Família sob a ótica da racionalidade limitada}

O Programa Bolsa Família (PBF) é um programa de transferência direta de renda com condicionalidades que beneficia famílias pobres (com renda mensal por pessoa de $\mathrm{R} \$ 60,01$ a $\mathrm{R} \$ 120,00$ ) e extremamente pobres (com renda mensal por pessoa de até R \$60,00) (Ministério de Desenvolvimento Social - MDS, 2006). Ele é pautado na articulação de três dimensões essenciais à superação da fome e da miséria. A primeira é a promoção do alívio imediato da pobreza por 
meio da transferência direta de renda à família. A segunda é o reforço ao exercício de direitos sociais básicos nas áreas de saúde e educação por meio do cumprimento das condicionalidades, o que contribui para que as famílias consigam romper o ciclo da pobreza entre gerações. Para que o beneficiário receba a porção monetária, as condições a se cumprir são: i) crianças e adolescentes da família entre 6 e 17 anos devem ter uma frequência escolar mínima; ii) crianças e adolescentes de até 15 anos em risco ou retiradas do trabalho infantil devem ter uma frequência mínima em atividades socioeducativas; iii) crianças menores de 7 anos devem cumprir o calendário de vacinas e fazer o acompanhamento de seu crescimento e desenvolvimento; iv) gestantes devem fazer o acompanhamento pré-natal; e v) nutrizes entre 14 e 44 anos devem fazer o acompanhamento de sua saúde (MDS, 2009). Por fim, a terceira dimensão é a coordenação de programas complementares que têm por objetivo o desenvolvimento das famílias, de modo que os beneficiários do PBF consigam superar a situação de vulnerabilidade e pobreza. São exemplos de programas complementares: programas de geração de trabalho e renda, de alfabetização de adultos, de fornecimento de registro civil e demais documentos.

Diante das dimensões conjunturais e estruturais do PBF, há dois pontos a se destacar. Primeiro, há evidências de que o programa tem obtido relativo êxito na promoção do alívio imediato da pobreza. Segundo, é possível vislumbrar mecanismos mais eficazes de estímulo à independência do beneficiário no longo prazo para com a transferência feita pelo programa.

\subsection{O impacto conjuntural do PBF}

Quanto à primeira constatação, alguns estudos apontam para certo grau de sucesso do PBF (IPEA, 2006; Marques, 2005; Marques; Mendes, 2008; Medeiros et al., 2007 e 2008; Soares et al., 2007). A transferência de renda, argumenta-se, tem de fato chegado a quem precisa e isso traz impactos imediatos no alívio da miséria e na distribuição da renda nas diversas formas em que é mensurada.

Neri $(2005$, p. 5), por exemplo, aponta que houve uma queda de $8 \%$ da miséria no Brasil, em 2004 e afirma:

Apesar de alguma desaceleração do crescimento do PIB e na geração de trabalho, a continuidade da expansão do Bolsa Família, atingindo 8,7 milhões de famílias no final de 2005 (11,6 milhões no final de 2006) e, em particular, o ganho real de $9 \%$ do salário mínimo já ocorrido em 2005, levarão a uma redução da miséria superior àquela observada em 2004.

A Tabela 1 apresenta algumas informações sobre a representatividade do PBF. Observa-se que aproximadamente 11,6 milhões de famílias estão sendo beneficiadas com a transferência de renda proporcionada pelo programa. Outras 
240 mil famílias recebem benefícios adicionais por meio de outros programas. Isso corresponde a cerca de um quarto da população brasileira. Há também estudos a respeito da eficácia da focalização do programa, indicando que ele de fato concentra a maior parte de seus recursos na transferência de renda às famílias mais pobres (CEDEPLAR, 2007; Medeiros et al., 2007; IBGE, 2008).

Tabela 1

Informações sobre o Programa Bolsa Família

\begin{tabular}{l|c|c}
\hline Discriminação & $\begin{array}{c}\text { Números } \\
2006\end{array}$ & $\begin{array}{c}\text { Números } \\
2009\end{array}$ \\
\hline População (estimativa IBGE 2004) & 182.059 .355 & 191.036 .129 \\
\hline $\begin{array}{l}\text { Estimativa Famílias Pobres - Perfil Bolsa Família (Renda per } \\
\text { capita familiar até R\$120,00) }\end{array}$ & 11.102 .763 & 12.995 .195 \\
\hline $\begin{array}{l}\text { Estimativa Famílias Pobres - Perfil Cadastro Único (Renda per } \\
\text { capita familiar até R\$ 175,00) }\end{array}$ & 16.068 .253 & 22.231 .781 \\
\hline Total de Famílias Cadastradas & 14.778 .374 & 18.579 .523 \\
\hline $\begin{array}{l}\text { Total de Famílias Cadastradas - Perfil Cadastro Único (Renda per } \\
\text { capita familiar até R\$ 175,00 em 2006 e até 1\2 salário mínimo } \\
\text { em 2009) }\end{array}$ & 14.265 .426 & 16.395 .854 \\
\hline $\begin{array}{l}\text { Total de Famílias Cadastradas - Perfil Bolsa Família (Renda per } \\
\text { capita familiar até R\$ 120,00) }\end{array}$ & 13.456 .701 & 17.843 .560 \\
\hline $\begin{array}{l}\text { Número de Famílias Beneficiárias do Bolsa Família - Benefício } \\
\text { liberado }\end{array}$ & 11.098 .076 & 11.611 .680 \\
\hline $\begin{array}{l}\text { Número de Famílias Beneficiárias do Bolsa Escola - Benefício } \\
\text { liberado }\end{array}$ & 70.654 & 179 \\
\hline $\begin{array}{l}\text { Número de Famílias Benefíciárias - Bolsa Alimentação - } \\
\text { Benefício liberado }\end{array}$ & 2.653 & 226.131 \\
\hline $\begin{array}{l}\text { Número de Famílias Benefíciárias do Auxílio-Gás-Benefício } \\
\text { liberado }\end{array}$ & 636.736 & 2.579 \\
\hline $\begin{array}{l}\text { Número de Famílias Benefíciárias do Cartão Alimentação- } \\
\text { Benefício liberado }\end{array}$ & & 14.686 \\
\hline Fonte• adaptado de MDS (vários anos) & & 2 \\
\hline
\end{tabular}

Fonte: adaptado de MDS (vários anos).

Como resultado, enxerga-se uma correlação entre os programas de redução da pobreza - dos quais o PBF é o de maior escala, como ilustrado na Tabela 1 - e os indicadores socioeconômicos correspondentes. A Figura 4 ilustra a situação, apresentando a queda do percentual de pessoas que vivem abaixo da linha de pobreza no Brasil pari passu à redução da desigualdade de renda tal qual medida pelo Coeficiente de Gini. ${ }^{11}$

(11) As linhas de pobreza extrema e/ou indigência apresentadas no Ipeadata são estimadas a partir da metodologia desenvolvida pela comissão IBGE-IPEA-CEPAL para se definir uma cesta básica de alimentos que satisfaça os requisitos nutricionais em cada região brasileira. A metodologia é apresentada no site www.ipeadata.gov.br. 
Figura 4

Coeficiente de Gini e percentual de pessoas vivendo abaixo da linha da pobreza*

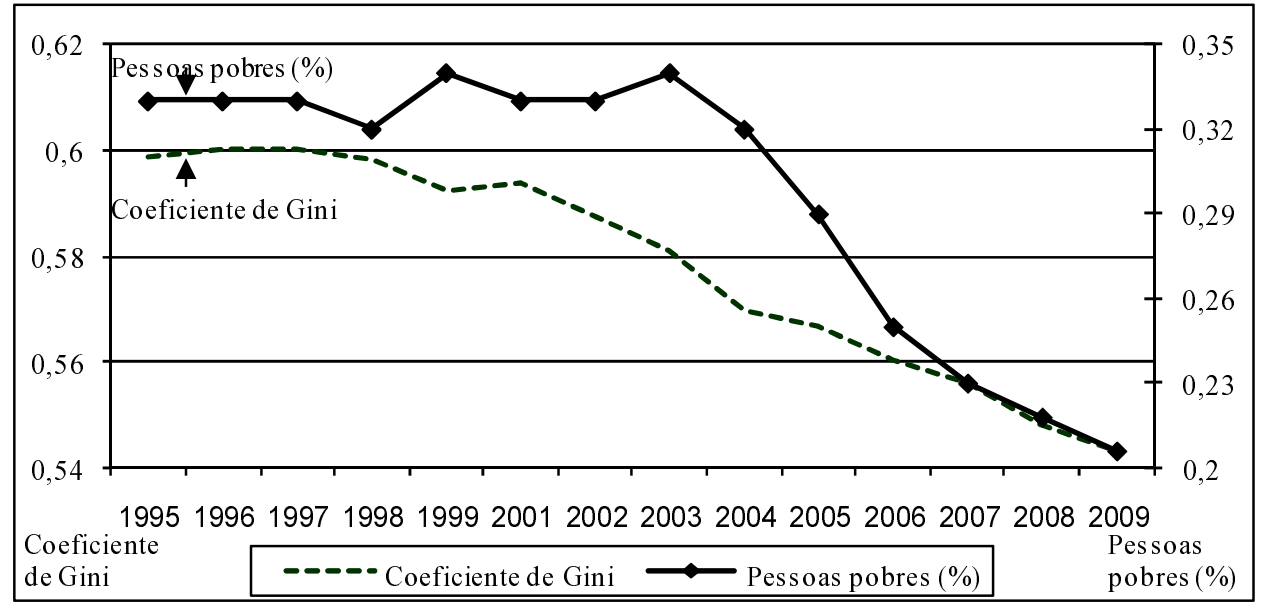

* os dados para o ano 2000 não estão disponíveis por conta da não realização da Pesquisa Nacional por Amostra de Domicílios (PNAD).

Fonte: a partir de dados do IBGE (vários anos) e do IPEA (vários anos).

Os indicadores apontam para uma melhoria frente ao período imediatamente posterior ao Plano Real, quando diversos estudos detectaram uma diminuição da pobreza. Isso se manteve estável até a queda acentuada e contínua a partir de 2003, ano da primeira mensuração após o início do PBF. O percentual de pessoas pobres caiu próximo a $30 \%$ em 2005 e chegou a 20,6\% em 2009, o menor índice apresentado pela série desde 1976, quando começou a ser elaborada.

No que se refere à concentração de renda, tal qual medida pelo Coeficiente de Gini, houve também uma queda que se manteve contínua a partir de 2001 . No período, a taxa de crescimento da economia brasileira foi tímida - média aproximada de 3,3 \% a.a. para o PIB e de 2,04 \% a.a. para o PIB per capita, entre 2001 e 2007. Os melhores desempenhos na queda da concentração estão em 2004 e 2007, quando a queda do Coeficiente foi mais acentuada $(-1,90$ e $-1,44 \%$ respectivamente) e o crescimento econômico mais expressivo.

Embora a queda da desigualdade não tenha necessariamente uma correlação direta com a queda da pobreza, parece possível enxergá-la para o caso brasileiro a partir de 2003. Barros et al. (2006), por exemplo, estimam que somente o PBF seja responsável por algo entre 8 e $18 \%$ da redução de desigualdade detectada desde sua implementação até 2004. O IPEA (2006) estima que o PBF contribuiu com $10 \%$ da redução de desigualdade de renda no Brasil até 2006 - uma contribuição semelhante à das transferências por aposentadorias e pensões cuja expansão custou de 4 a 5 vezes os recursos empregados no PBF. Soares et al. (2006) estimam que essa contribuição possa ter chegado a $21 \%$. 
Os resultados dos estudos empíricos, portanto, apresentam indícios positivos sobre a contribuição do PBF na queda da pobreza e desigualdade em perspectiva conjuntural. Cabe ressaltar que, após 2004, a economia brasileira apresentou taxas de crescimento econômico superiores às observadas nas últimas três décadas, o que tende a favorecer a queda do nível de pobreza absoluta. O histórico da economia brasileira, entretanto, é composto por diversos períodos nos quais elevadas taxas de crescimento econômico foram acompanhadas pelo aumento da desigualdade.

\subsection{O impacto estrutural do PBF}

O segundo ponto a destacar envolve o desenho institucional do PBF. Interessa aqui entender a qualidade de suas ações frente a possibilidades de mudança estrutural. Uma vez identificadas evidências de que o programa tem obtido êxito no alívio imediato da pobreza, cabe avaliar seus mecanismos de estímulo à independência do beneficiado no longo prazo, por meio não apenas da ampliação da cesta de bens, mas também de sua capacidade de reavaliar qualquer cesta que se lhe apresente.

A história do PBF nos remete a alguns programas de transferência de renda anteriores, como o Bolsa Escola. O Bolsa Escola foi implementado no governo Fernando Henrique em 2001, a partir da experiência iniciada pelo então governador do Distrito Federal, Cristóvam Buarque em 1995. Vaz (2006), por exemplo, afirma que o Bolsa Escola contribui para o alívio da miséria ao estimar que seus beneficiários passaram a gastar mais com alimentação do que antes, entendendo que o acréscimo de renda serviu para suprir as famílias com bens básicos aos quais não tinham acesso. A única condição imposta era a frequencia escolar dos filhos entre 6 e 15 anos. A condicionalidade visava tirá-los do trabalho que servia para complementar a renda da família e incentivá-los a sair do círculo vicioso da pobreza via construção de competências. Este último objetivo, obviamente, é o que impõe maiores obstáculos à mensuração (Medeiros et al., 2008).

O governo Lula, iniciado em 2003, trouxe um discurso de prioridade ao combate à fome e implementou o programa Fome Zero. Diante de problemas em sua execução, decidiu-se incorporá-lo à estrutura já estabelecida de políticas de transferência de renda. Buscou-se, a partir daí, integrar todas as iniciativas em um único cadastro com a constituição do Bolsa Família. Observa-se que o programa unificado ampliou significativamente não só as transferências de renda após 2003, como também as condicionalidades (como visto no início da seção).

De acordo com o MDS (2006), em informações disponibilizadas na página oficial do PBF, os principais resultados do programa são: i) manutenção de seu 
foco, ou seja, ele efetivamente chega às famílias que dele necessitam e atendem aos critérios da lei; ii) contribuição significativa à redução da pobreza extrema e desigualdade; e iii) contribuição para a melhoria da situação alimentar e nutricional das famílias beneficiárias.

Em suma, os resultados apresentados no momento restringem-se ao alívio imediato da pobreza. Obviamente, espera-se que o alívio da pobreza por um período mais prolongado, por si só, dê às famílias mais tempo e melhores condições neurofisiológicas de buscar atividades que possam thes prover perspectivas futuras. Tais iniciativas, no entanto, continuam reféns de hábitos de pensamento, limitações de informação e racionalidade.

As condicionalidades com maior potencial para influenciar a mudança de hábitos de pensamento e criação de competências aplicam-se aos filhos das famílias beneficiárias (a frequência escolar continuada). Assim, é de se esperar que os impactos do PBF sobre tais variáveis só possam ser razoavelmente mensurados após um ciclo escolar completo (Medeiros et al., 2008). Como explica Albert Hirschman (1980), é possível que alguns indicadores piorem antes de apresentarem melhora. Isso, porém, não pode ser de imediato identificado como uma falha estrutural do Programa. ${ }^{12} \mathrm{O}$ mais recente estudo sobre os impactos do PBF (CEDEPLAR, 2007), por exemplo, expõe várias dificuldades em se obter estimativas razoáveis desses impactos. Esse mesmo estudo, no entanto, aponta para mudanças de hábitos nos gastos da família, mesmo quando sua renda líquida não tenha sido substancialmente alterada. ${ }^{13}$

No que tange aos adultos das famílias beneficiárias, construir uma estrutura voltada à mudança estrutural parece mais complexo. Tanto a Lei 10.836, de 09 de janeiro de 2004, que cria o PBF, quanto o decreto n. 4.714 de 2003, que cria a Câmara de Política Social do Conselho de Governo da Presidência da República, estipulam uma articulação entre o PBF e outros programas complementares. O público adulto de beneficiários, porém, é heterogêneo em vários aspectos e, geralmente, arrima a família. ${ }^{14}$ Esses motivos dificultam cobrar dos adultos condicionalidades relativas à educação formal continuada. $\mathrm{O}$ rol de programas complementares, então, tem variado, apresentando principalmente opções de formação rápida para trabalho pouco qualificado, alfabetização e educação básica, subsídios variados para bens elementares e acesso ao crédito.

De fato, a heterogeneidade das condições pessoais, das realidades locais e flutuações do ambiente econômico parecem condicionar a natureza dos programas

(12) A isto Hirschman (1980, p.113) chama de "falácia estruturalista",

(13) Muitas famílias perderam a renda do trabalho infantil devido às condicionalidades do PBF

(14) Em adição ao próprio benefício do PBF, considerando a incompatibilidade de se ter crianças ao mesmo tempo na escola e em alguma atividade remunerada que seja o sustento principal da família. 
complementares e exigir que sejam revistos e refeitos continuamente. O Programa Nacional de Fortalecimento da Agricultura Familiar (PRONAF), por exemplo, volta-se ao meio rural, o que também se mostra ser a ênfase do Programa Territórios da Cidadania. Parte importante da pobreza no Brasil, porém, está na área urbana, conforme demonstram Del Grossi et al. (2001) ao analisarem a evolução da pobreza no Brasil. Nesse âmbito, por exemplo, não se viu ainda um envolvimento explícito de programas complementares aliados ao Ministério das Cidades. Enfim, a questão intergeneracional condiciona certas possibilidades do PBF. Talvez, os programas complementares sejam capazes de viabilizar à geração de adultos beneficiados opções anteriormente inviáveis, reduzindo limitações de racionalidade e assimetrias de conhecimento e informação. Não parece simples, porém, reverter certas inércias de hábitos e competências já consolidadas pelo tempo.

Sob tal aspecto, um ponto a analisar-se é se o atual desenho do PBF é ou não adequado a promover tanto os objetivos de alívio imediato da pobreza quanto os de melhorias estruturais. Em outras palavras, o PBF contém elementos que contribuem para ampliar as competências dos beneficiários quanto à tomada de decisão e, assim, elevar seu bem-estar a ponto de torná-los inelegíveis no futuro? Uma questão positiva do programa é que as condições a serem cumpridas relacionam-se ao acesso à melhor educação e saúde dos mais jovens. Dessa forma, entende-se que as condicionalidades estão na direção correta, na tentativa de conduzir algumas pessoas da família a escolhas intertemporais superiores.

É razoável esperar que as demandas conjunturais de alívio à pobreza tenham primazia no desenho do programa em um primeiro momento e, assim, sejam evidentes suas limitações ou insuficiências quanto à preocupação com as mudanças estruturais imaginadas. É razoável esperar que, com o tempo, o desenho do programa passe a refletir tal preocupação. Considere-se que há, por exemplo, custos de avaliação e monitoramento, e de geração de indicadores de estímulo de entrada e saída ao público beneficiário. Há, portanto, custos e benefícios em se alterar o desenho do programa. Considere-se também que as mudanças estruturais imaginadas no PBF são esperadas para um intervalo de tempo relativamente distante (ao menos um ciclo escolar completo). Diante disso, parece haver ao menos duas frentes para que o desenho institucional do PBF avance: a) maior atenção aos mecanismos de estímulo à emancipação dos beneficiados adultos; ${ }^{15}$ b) maior atenção ao processo de monitoramento e avaliação do rendimento educacional dos filhos das famílias beneficiadas.

(15) De acordo com a Lei do PBF, isso compete ao Conselho Gestor Interministerial do Programa Bolsa Família. Não há, porém, até o momento, objetivos bem definidos quanto às iniciativas e avaliação dessas ações. Aqui, obviamente, não há referência aos mecanismos de cancelamento do benefício ou exclusão do programa por não atendimento das condicionalidades. 
Quanto à primeira frente, uma informação relevante ao beneficiário é o limite de sua participação no programa. Isso não implica na criação de expectativas de punição, mas de opções melhores no futuro que dependam, conjuntamente, do esforço do indivíduo e da assistência prestada pelo programa. A formação de preferências intertemporais das pessoas pode assim ser afetada, dando maior peso à sombra do futuro e incitando maior comprometimento presente (Axelrod, 1984). Há, ainda, a possibilidade de os filhos se emanciparem da família original. Com a divisão da família, os adultos podem tornar-se inelegíveis, sem outras expectativas de melhoria, ficando à mercê de suas limitações iniciais e talvez em condições materiais ainda piores.

$\mathrm{Na}$ segunda frente, como vários autores já destacaram, a frequencia escolar das crianças não garante seu aproveitamento mínimo necessário para vislumbrar melhores perspectivas quanto a suas escolhas no longo prazo. Tal fragilidade aponta para a necessidade de transformar o compromisso para com a formação básica e/ou profissionalizante dos beneficiários em um mecanismo mais explícito no desenho do programa. Com isso, será possível estimar, ao menos no fim de um primeiro ciclo escolar, o impacto do PBF. O estudo realizado pelo CEDEPLAR (2007) é um passo nessa direção, mas talvez falte consolidar um mecanismo permanente de acompanhamento.

Vendo o PBF como uma política pública que considera a limitação da racionalidade dos indivíduos, ${ }^{16}$ pode-se dizer que o formato de transferência condicionada de renda satisfaz, em parte, a perspectiva do paternalismo libertário. Um próximo passo do programa, principalmente a partir do momento em que o número de beneficiários efetivos aproxima-se do número dede beneficiários efetivos aproxima-se do número de beneficiários potenciais, mais atenção é necessário ao processo de emancipação dos mesmos, ainda que isso só seja contemplado para alguns anos à frente. Essa necessidade precisa ser incorporada ao desenho institucional do programa, seja pelas condicionalidades, regras adicionais de emancipação ou por compromissos para com resultados no médio e no longo prazo. Prazos que precisam ser estabelecidos e resultados, dimensionados de modo a viabilizar o acompanhamento constante do programa. Isso auxilia o programa em duas frentes. Primeiro, ajuda a justificá-lo em conjunturas políticas diversas. Segundo, dá subsídios a ajustes bem informados do desenho do programa em resposta ao comportamento dos agentes envolvidos, cuja

(16) Outra forma de considerar-se a opção pela condicionalidade é assumir que os beneficiários deparam-se com uma elevada taxa de desconto para o consumo futuro, em virtude do baixo nível de renda e consequente baixa perspectiva com relação às possíveis oportunidades de ampliação de seu nível de bem-estar ao longo do tempo. Isso os fará dar peso excessivo ao curto prazo. Pode-se, ainda, assumir que os mesmos sofrem de "miopia" intertemporal. O fato é que, em qualquer dos casos, a questão relevante é como alterar o comportamento dos agentes via preferências intertemporais, estimulando-os, por exemplo, a alocarem mais recursos na educação dos filhos. 
predeterminação normativa, como se argumenta aqui, tem limitada utilidade para o analista.

\subsection{Microeconomia paternalista e libertária: um comparativo entre os dois modelos considerados}

Diante do quadro apresentado, retoma-se a questão microeconômica a respeito do comportamento dos indivíduos discutida nas seções anteriores. Uma questão a ser tratada nesse tipo de política refere-se à melhoria da capacidade de decisão dos indivíduos beneficiados. Tal aspecto, por um lado, visa a propiciar condições para melhorar suas escolhas, por outro, oferecer algum estímulo ou apoio para que se capacite a exercer atividades de melhor retorno e obter renda de forma sustentável por meios próprios.

Partindo-se da hipótese de que os beneficiários são racionais no sentido estrito e maximizam sua utilidade dada uma dotação, deixa-se de lado a questão da formação de preferências. Supõe-se que o indivíduo toma a decisão que mais the convém, mas desconsidera-se que ele poderia ter outra escolha diante de mais informações, maior capacitação ou mesmo de uma simples mudança na apresentação das opções que lhe são oferecidas.

As pessoas contempladas nos critérios de elegibilidade do PBF, em geral, deparam-se com dificuldades severas à sobrevivência. Isso, por certo, as conduz ao desenvolvimento de habilidades para superar condições adversas, o que poderá ser entendido como uma melhoria de suas capacidades decisórias. Tal fato, contudo, ficará restrito às dificuldades que se apresentam no âmbito imediato de sobrevivência, em um ambiente que the é dado e estático. Diante da falta de perspectiva de mudança do ambiente, a única novidade é a transferência de renda. Assim, o beneficiário maximizará resultados dentro das condições de vida propiciadas pela transferência de renda e continuará desconhecendo as possibilidades de mudança do quadro existente. Isso o deixará no equilíbrio estático do quadro de pobreza com transferência de renda. No esforço de maximizar seu resultado, o beneficiário poderá ver-se na situação em que o custo marginal (resultado do esforço necessário para tornar-se inelegível somado à perda da renda obtida pelo programa) seja maior do que o benefício marginal (resultado esperado do ganho obtido com o esforço para sair do programa somado ao ganho advindo do exercício de sua força de trabalho) - uma armadilha da pobreza.

Isso poderá acontecer por uma limitação da racionalidade econômica do agente em tomar decisões intertemporais. Seu desconhecimento das possibilidades do mercado de trabalho ou a falta de perspectivas com relação ao mesmo, por exemplo, poderão deixá-lo apenas em um ótimo local, ou mesmo em uma trajetória não ótima em termos de eficiência dinâmica. No linguajar da economia 
comportamental, o indivíduo é um satisficer que busca certo nível de aspiração e nele pode se acomodar. Ele só poderá tomar decisões intertemporais ótimas ou elevar o nível de aspiração se suas preferências por resultados futuros tiverem mais peso na decisão presente ou se aumentar a perspectiva de ganhos futuros fora do programa. Tal decisão lhe demandará mudanças comportamentais derivadas de mudanças de preferências que, por sua vez, poderão derivar de mais e melhores informações ofertadas. Como visto acima, a forma de apresentação das informações é relevante para a tomada de decisão, principalmente na formulação de uma opção default e, por sequência temporal, na possível existência de inércia comportamental ou de um efeito dotação (Sunstein; Thaler, 2003; Kahneman et al., 1990).

Dessa forma, retomando Thaler; Sustein (2003), medidas paternalistas que ampliem as possibilidades e preservem a liberdade de escolha e, ao mesmo tempo, estimulem os beneficiários a contemplar o longo prazo têm seus atrativos. Tais medidas podem incluir a própria exigência de alguma contrapartida, o fornecimento de informações relativas a ações vistas como importantes para o bem-estar social ou a promoção de merit goods. O Quadro 1 apresenta um comparativo dos aspectos paternalista e libertário das duas formas de políticas compensatórias aqui consideradas.

Quadro 1

Comparativo entre diferentes formas de políticas compensatórias

\begin{tabular}{|l|c|c|}
\hline & $\begin{array}{c}\text { Transferência exclusiva de } \\
\text { renda monetária }\end{array}$ & $\begin{array}{c}\text { Transferência de renda monetária com } \\
\text { exigência de contrapartidas }\end{array}$ \\
\hline Paternalista & Sim & Sim \\
\hline \multirow{2}{*}{ Libertário } & $\begin{array}{c}\text { No curto prazo: ampliação das } \\
\text { escolhas em um ambiente dado. }\end{array}$ & $\begin{array}{c}\text { No curto prazo: ampliação das escolhas em } \\
\text { um ambiente dado, condicionada às } \\
\text { exigências de contrapartidas. }\end{array}$ \\
$\begin{array}{c}\text { incorrer-se na armadilha da } \\
\text { pobreza - as escolhas, } \\
\text { anteriormente ampliadas, não } \\
\text { podem mais ser ampliadas. }\end{array}$ & $\begin{array}{c}\text { No longo prazo: ampliação das escolhas com } \\
\text { maior possibilidade de mudança das } \\
\text { competências e preferências individuais, } \\
\text { portanto, do ambiente. }\end{array}$ \\
\hline
\end{tabular}

Nesse caso, cabe observar que não se trata apenas de um problema de informações incompletas por parte dos beneficiários. Eles podem ter informações perfeitas sobre os ganhos potenciais oriundos das contrapartidas exigidas pelo programa e, ainda assim, determinar um peso relativamente maior ao bem-estar no curto prazo, deparando-se com a armadilha da pobreza.

Supondo que aquela seja a preferência do indivíduo, então, ele a expressará como sua opção ótima. Imagina-se ser possível, porém, que as contrapartidas possam melhorar seu bem-estar econômico no longo prazo. Se ele 
optar por não realizá-las (esse tipo de risco justificaria a condicionalidade), resta supor que há algo não considerado pela análise a respeito de suas próprias preferências.

Tal discrepância não se dá apenas vis-à-vis a preferências sociais em função das possíveis externalidades positivas, mas está diretamente relacionada aos benefícios próprios. Além das externalidades positivas proporcionadas pelas contrapartidas, há também ganhos para os próprios indivíduos com a ampliação das escolhas no longo prazo. Isso porque se exige maior comprometimento com a melhoria de ações preventivas para saúde, educação e o próprio esforço para superar as condições de elegibilidade de um programa assistencialista.

As condicionalide desse tipo de programa, portanto, não precisam ser vistas apenas como mecanismo de correção de falhas de mercado, procurando alcançar possíveis externalidades positivas. De modo diferente, elas também podem ser vistas como uma forma de direcionar a decisão dos indivíduos a seu próprio bem. Afinal, uma escolha intertemporal tende a apresentar elementos complexos com os quais um indivíduo pode não ser plenamente capaz de lidar de forma a atingir um nível ótimo de bem-estar ao longo do tempo. Sendo assim, esse tipo de ação caracteriza-se como paternalista e libertária ao aumentar a liberdade de escolha para com a assistência financeira no curto prazo (o que é, obviamente, relevante) e, também, a liberdade de escolhas no longo prazo - algo que, inclusive, caracteriza a visão moderna.

\section{Comentários finais}

A elaboração de políticas públicas voltadas ao combate à pobreza enfrenta uma série de complexidades que encontram orientação limitada no campo da economia normativa. Um ponto relevante ao tema é a forma como o elaborador de políticas enxerga o comportamento econômico do beneficiário. Nesse sentido, a teoria microeconômica descritiva, voltada a compreender o comportamento do indivíduo, pode trazer algumas contribuições relevantes. Tais contribuições podem ser discutidas no âmbito do processo de planejamento e definição das regras do jogo que envolvem os critérios de elegibilidade, das ações efetivas do programa, da forma como os benefícios são providos e dos mecanismos de exigência de contrapartidas.

Ao se considerar os potenciais beneficiários como agentes econômicos racionais, mas com dificuldades inatas para tomar suas decisões, é possível incorporar, no desenho do programa, elementos que não seriam contemplados a partir da teoria normativa. Analisando o caso específico do Programa Bolsa Família, observa-se uma tentativa nessa direção, com a inclusão de condicionalidades para a concessão do benefício. Há, contudo, espaço para 
melhorá-lo, na direção de apoiar os elegíveis a superar a situação de vulnerabilidade e pobreza, portanto, de dependência com relação ao programa.

Assim, seria oportuno avançar em medidas que permitam aos beneficiários permanecerem com a liberdade de escolha frente aos benefícios concedidos, mas não só. Seria ainda mais oportuno incluir incentivo que, de certa forma, questionem as preferências estabelecidas, geralmente, concentradas no curto prazo e realçar que isso amplia as liberdades futuras de escolha em um patamar mais elevado de aspiração de bem-estar.

A transferência de renda condicionada a contrapartidas permite a promoção da mudança de competências e preferências, ou seja, tem maior potencial de efeitos benéficos no longo prazo sobre o comportamento dos beneficiários e, quiçá, de seus descendentes. As contrapartidas hoje requeridas pelo PBF apontam para essa direção. Elas, porém, não parecem eximir o programa de certa fragilidade quanto a ir além do alívio imediato da pobreza. Se, por um lado, a transferência de renda não parece suficiente para transcender o alívio imediato da pobreza, por outro, a exigência atual de contrapartidas atuais e a complementação de programas de assistência parecem um avanço.

Um próximo passo deverá contemplar a possibilidade de atuar nos mecanismos de incentivo e apoio para persuadir os beneficiários das vantagens em se alcançar a independência para com o PBF no longo prazo. Se o Programa pretende promover uma mudança estrutural das condições nas quais seus beneficiários encontram-se, estratégias hoje vistas como complementares (e.g. as frentes relativas à educação, emprego e geração de renda local) tornar-se-ão mais relevantes e, talvez, devam ser contempladas mais incisivamente no desenho dos mecanismos de incentivo. Não se pode, porém, perder de vista os condicionantes do processo decisório dos beneficiários. É importante que se continue buscando ampliar sua capacidade, tomar decisões intertemporais que conciliem o aumento de seu próprio bem-estar, da família e da sociedade.

\section{Referências bibliográficas}

AXELROD, Robert. La evolución de la cooperación: el dilema del prisionero y la teoria de juegos. Madrid: Alianza, 1984 [1986].

BARROS, R.; CARVALHO, M.; FRANCO, S.; MENDONÇA, R. Uma análise das principais causas da queda recente na desigualdade de renda brasileira. Rio de Janeiro: IPEA, 2006. (Texto de discussão, n. 1203).

CEDEPLAR. Sumário executivo - avaliação de impacto do Programa Bolsa Família. Secretaria de Avaliação e Gestão da Informação, Ministério do Desenvolvimento Social e Combate à Fome, 2007.

CHOI, J.; LAIBSON, D.; MADRIAN, B.; METRICK, A. Optimal defaults. American Economic Review, v. 93, n. 2, p. 180-186, 2003. 
DEL GROSSI, M.; SILVA, J.; TAKAGI, M. A evolução da pobreza no Brasil: 1995/99. Campinas: Unicamp. Instituto de Economia, 2001. (Texto de Discussão).

DOLFSMA, W.; FINCH, J; McMASTER, R. Market and society: how do they relate, and how do they contribute to welfare? Journal of Economic Issues, v. 39, n. 2, p. 347-358, 2005.

HIRSCHMAN, A. The welfare state in trouble: systemic crisis or growing pains? American Economic Review, v. 70, n. 2, p. 113-116, 1980.

IBGE - Instituto Brasileiro de Geografia e Estatística. Acesso a transferências de renda de programas sociais. Resultados da Pesquisa Nacional por Amostra de Domicílios PNAD de 2006. Rio de Janeiro: IBGE, 2008.

. Indicadores. Vários anos. Disponível em: http://www.ibge.gov.br.

IPEA - Instituto de Pesquisa Econômica Aplicada. Nota técnica sobre a recente queda da desigualdade. Brasília: IPEA, 2006.

. Ipeadata. Vários anos. Disponível em: http://www.ipeadata.gov.br.

KAHNEMAN, Daniel. New challenges to the rationality assumption. Journal of Institutional and Theoretical Economics, 150, p. 18-36, 1994.

KAHNEMAN, D.; TVERSKY, A. On the psychology of prediction. Psychological Review, 80, p. 237-251, 1973.

; KNETSCH, J.; THALER, R. Experimental tests of the endowment effect. Journal of Political Economy, 98, p. 1325-1348, 1990.

bias. Journal of Economic Perspectives, 5, p. 193-206, 1991.

KERSTENETZKY, Célia. Políticas sociais: focalização ou universalização? Revista de Economia Política, v. 26, n. 4, p. 564-574, 2006.

Redistribuição e desenvolvimento? A economia política do Programa Bolsa Família. Dados, v. 52, n. 1, p. 53-83, 2009.

LE GRAND, Julian. Equity and choice: an essay in economics and applied philosophy. London: HarperCollins Academic, 1991.

MADRIAN, B.; SHEA, D. The power of suggestion: inertia in 401(k) participation and savings behavior. Quarterly Journal of Economics, v. 116, n. 4, p. 1149-1187, 2001.

MARQUES, Rosa. A importância do Bolsa Família nos municípios brasileiros. Cadernos de Estudos - Desenvolvimento Social em Debate, 1, p. 8-40, 2005.

; MENDES, A. Sobre a política de combate à pobreza no Governo Lula. Revista de Economia, v. 34, n. 3, p. 89-109, 2008.

MATTHEWS, R .C. O. Morality, competition and efficiency. The Manchester School of Economic \& Social Studies, v. 49, n. 4, p. 289-309, 1981.

MDS - Ministério do Desenvolvimento Social. Vários anos. Disponível em: http://www.mds.gov.br. 
MEDEIROS, M.; BRITTO, T. SOARES, F. Transferência de renda no Brasil. Novos Estudos-CEBRAP, São Paulo, 79, p. 5-21, 2007. ;__ _ _ Targeted cash transfer programmes in Brazil: BPC and the Bolsa Família. Brasília: International Poverty Centre, 2008. (IPC Working Paper).

MONNERAT, G.; SENNA, M.; SCHOTTZ, V.; MAGALHÃES, R.; BURLANDY, L. Do direito incondicional à condicionalidade do direito: as contrapartidas do Programa Bolsa Família. Ciência \& Saúde Coletiva, v. 12, n. 6, p. 453-462, 2007.

NERI, Marcelo. Miséria em queda: mensuração, monitoramento e metas. Centro de políticas sociais. Rio de Janeiro: Fundação Getúlio Vargas, 2005. Disponível em: http://www.fgv.br/cps. Acesso em: 10 jan. 2007.

PESSALI, H.; FERNÁNDEZ, R. Inovação e teorias da firma. In: PELAEZ, V.; SZMERECSÁNYI, T. (Org.). Economia da inovação tecnológica. São Paulo: Hucitec, 2006. p. 302-332.

ROCHA, Sonia. Pobreza no Brasil: afinal, de que se trata? Rio de Janeiro: FGV, 2003.

SIMON, Herbert. Administrative behavior. New York: The Macmillan Company, 1947.

SOARES, F.; RIBAS, R.; OSÓRIO, R. Evaluating the impact of Brazil's Bolsa Familia: cash transfer programmes in comparative perspective. Evaluation Note 1. Brasília: International Poverty Centre, 2007.

; SOARES, S.; MEDEIROS, M.; OSÓRIO, R. Programas de transferências de renda no Brasil: impactos sobre a desigualdade. In: ENCONTRO NACIONAL DE ECONOMIA, 34, Salvador, 5-8 dez. 2006. Anais...

SUNSTEIN, C.; THALER, R. Libertarian paternalism is not an oxymoron. University of Chicago Law Review, v. 70, n. 4, Summer, p. 1159-1202, 2003.

THALER, R.; SUNSTEIN, C. Libertarian paternalism. American Economic Review, v. 93, n. 2, p. 175-179, 2003.

TVERSKY, A.; KAHNEMAN, D. Rational choice and the framing of decisions. Journal of Business, 59, p. 251-278, 1986.

VAZ, Bruno. Efeito do Programa Bolsa Escola sobre as despesas das famílias. Dissertação (Mestrado)-Pós-Graduação em Economia, PUC-Rio, Rio de Janeiro, 2006. 